\title{
Premature atherosclerosis in children with beta-thalassemia major: New diagnostic marker
}

\author{
Laila M. Sherief ${ }^{1 *}$, Osama Dawood ${ }^{2}$, Adel Ali $^{3}$, Hanan S. Sherbiny ${ }^{3}$, Naglaa M. Kamal ${ }^{4}$, Mohamed Elshanshory ${ }^{5}$,
} Osama Abd Alazez ${ }^{6}$, Mohamed Abd Alhady ${ }^{3}$, Mohamed Nour ${ }^{3}$ and Wesam A. Mokhtar ${ }^{3}$

\begin{abstract}
Background: Early vascular alteration, atherosclerosis and coronary artery disease have emerged as important cardiovascular complications among beta-thalassemia major (B-TM) patients. The aims of the current study were to assess the prevalence of premature atherosclerosis among our B-TM patients, and to investigate the diagnostic value of serum Osteoprotegerin assay as an early biomarker for atherosclerosis.

Methods: This cross-sectional study was conducted at Hematology unit - Pediatric Department, Zagazig University Children Hospital- Egypt in the period from March 2014 to March 2015. A total of 115 children were enrolled in the current study; as sixty-five (65) children with beta thalassemia major aged 5-18 years, on regular blood transfusion regimen represented the patient group. While fifty (50) healthy children, with comparable age and gender, were assigned as control group. All participants were subjected to history taking, thorough clinical examination and laboratory investigations including; complete blood count, liver and kidney function tests, C- reactive protein, lipid profile, serum ferritin and serum Osteoprotegerin (OPG) assay. Also, carotid artery intima media thickness (CAIMT) was performed by duplex ultrasound for patients and controls.
\end{abstract}

Results: Our B-TM patients were transfusion-dependent for as long as $8.5 \pm 3.8$ years with significantly higher serum ferritin levels ( $2490 \pm 1579 \mathrm{ng} / \mathrm{dl}$ vs $83 \pm 32 \mathrm{ng} / \mathrm{dl}, p=0.001)$, C-reactive protein (5.7 \pm 5.7 vs $0.9 \pm 0.9$ ), liver enzymes and bilirubin when compared to controls. Significantly higher serum triglyceride $(128 \pm 20 \mathrm{vs} 101 \pm 7 \mathrm{mg} / \mathrm{dL}, p=0$. $009)$ and atherogenic index of plasma ( $0.45 \pm 0.12$ vs $0.22 \pm 0.04, p=0.001)$ were recorded in patients than comparisons. On the contrary, total serum cholesterol (116 \pm 16 vs $143 \pm 5, p<0.001)$, low density lipoproteincholesterol (LDL-C) $(44 \pm 9$ vs $73 \pm 6, p<0.001)$ and high density lipoprotein cholesterol (HDL-C) $(39 \pm 2$ vs $61 \pm 5$, $p<0.001$ ), were significantly lowered in patients versus normal peers. Carotid arteries intima media thickness (CAIMT) of both side were significantly increased for patients (Rt $0.62 \pm 0.2$ vs. $0.29 \pm 0.07 \mathrm{~mm}, p=0.001$ \& Lt $0.66 \pm 0.17$ vs 0.29 $\pm 0.05 \mathrm{~mm}, p=0.001$ ) when compared with healthy controls, and showed positive correlation with, serum triglyceride, atherogenic index of plasma, and serum Osteoprotegerin levels. ELISA assay of serum Osteoprotegerin (OPG) revealed significantly higher levels for thalassemia patients than matched healthy controls $(427 \pm 102 \mathrm{vs} .324 \pm 126 \mathrm{pg} / \mathrm{ml}, p=0$. 02). Of particular interest is the obvious positive correlation between OPG levels and CAIMT of both sides (Rt r $0.54, p=0.001 \& L t$ r $0.479, p=0.001$ ) and also with serum triglycerides ( $0.374, p=0.03$ ).

(Continued on next page)

\footnotetext{
* Correspondence: Lamesh25@yahoo.com

${ }^{1}$ Pediatrics and Pediatric Hematology and Oncology, Faculty of Medicine,

Zagazig University, Zagazig, Egypt

Full list of author information is available at the end of the article
} International License (http://creativecommons.org/licenses/by/4.0/, which permits unrestricted use, distribution, and reproduction in any medium, provided you give appropriate credit to the original author(s) and the source, provide a link to the Creative Commons license, and indicate if changes were made. The Creative Commons Public Domain Dedication waiver (http://creativecommons.org/publicdomain/zero/1.0/) applies to the data made available in this article, unless otherwise stated. 
(Continued from previous page)

Conclusions: Subclinical atherosclerosis started prematurely in children with beta- thalassemia. Carotid artery intima media thickness represented a simple, accurate and non-invasivemodality for early detection ofatherosclerosis. It was correlated well with serum Osteoprotegerin; this finding highlighted the possible validity of OPG assay as an early predictor of atherosclerosis in thalassemia children.

Keywords: Beta-thalassemia, Carotid artery intima media thickness, Osteoprotegerin, premature atherosclerosis

\section{Background}

Beta-thalassemia represents the commonest cause of hemolytic anemia in Egypt with carrier rate ranges from 9$10 \%$ [1]. Beta- thalassemia major (B-TM) patients usually present within the first two years of life with severe anemia requiring regular red blood cell transfusions [2]. Early vascular alteration, atherosclerosis and coronary artery diseases have emerged as important cardiovascular complications among B-TM patients [3].

Atherosclerosis is a slow progressive disease that may start at childhood [4]. In atherogensis, arterial wall morphological changes occur during a presumably long subclinical lag phase, and characterized by gradual thickening of the intima [5]. Beside the traditional diagnostic methods such as angiography and stress-testing [6], measurement of the intima-media thickness of the large arteries, especially the carotids, has emerged as one of the method of choice for determining the anatomical extent of arterial wall deterioration and for assessing cardiovascular risk [5]. Several investigators have recommended the clinical use of this technique for detecting subclinical (asymptomatic) atherosclerosis and for identifying subjects at high-risk [7-9].

Circulating markers of atherosclerosis are associated with increased vascular risk; one of the new biomarkers of atherosclerosis is Osteoprotegerin (OPG) [10]. Osteoprotegerin is a cytokine of the tumor necrosis factor (TNF) receptor superfamily and is classed as an osteoclastogenesis inhibiting factor [11]. In the endothelial cell, OPG is associated with Von-Willebrand factor within secretory granules called Weibel-Palade bodies. Upon stimulation with TNF or interleukin-1 in vitro, the OPG- Von-Willebrand factor complex is secreted in the surrounding growth medium. This endothelial activation by pro-inflammatory cytokines is one of the possible sources of circulating OPG in patients with active atherosclerosis [12]. Moreover, in view of the role of vascular smooth muscles in atherosclerosis and intimal calcification, it is likely that, they are the main source of increased circulating OPG noted in cardiovascular disease [13]. Data suggest that OPG is induced by atherosclerosis and may be upregulated as an incomplete compensatory response to the vessel insult, possibly thereby limiting vascular calcification [14]. Osteoprotegerin seems to prevent arterial calcification but is not able to reverse calcification once it has occurred [15].
As the maximal potential for prevention and reversibility of atherosclerosis would be expected by intervention at early subclinical stage of the disease, its early diagnosis in high-risk individuals should be a research priority. The aims of the current work are; to assess the frequency of premature subclinical atherosclerosis in Egyptian B-TM patients by determining their carotid artery intima-media thickness, to figure-out the associated clinical and laboratory risk factors, and to evaluate the validity of OPG assay as a new biomarker for early diagnosis of atherosclerosis in these high-risk population.

\section{Methods \\ Patients}

We carried out this cross-sectional, case-control study on sixty -five (65) Beta-thalassemia major patients aged 5-18 years old. They were on regular follow-up at the Hematology Unit of Pediatric Department, Zagazig University Children Hospital- Egypt during the period from March 2014-March 2015. Fifty (50) apparently healthy children with comparable age and gender distribution were enrolled as controls.

Thalassemia patients enrolled in the current work were on regular red cell transfusion regimen, 33 cases were transfused every 4 weeks, while 22 and 10 cases were transfused every 3 weeks and 2 weeks respectively to keep their target haemoglobin [16].

All subjects in our study were questioned for known risk factors for atherosclerosis, patients with history of smoking, hepatic, renal or cardiac diseases were excluded. Also those with diabetes mellitus or other endocrinopathies, other hemoglobinopathies, familial hypercholesterolemia or premature atherosclerosis in their families were also excluded.

The study protocol was approved by the research and ethical committee of Faculty of Medicine, Zagazig University and written informed consent was taken from parents or guardian of each participant.

\section{Methods}

All eligible children (patients and controls) were subjected to; history taking with special emphasis on demographic characteristics, disease duration, frequency of transfusions, iron chelation regimen including type, dose, duration and compliance. Thorough clinical examination 
including anthropometric measures and all system evaluation were performed. Routine laboratory investigations for follow up thalassemia patients that included; complete blood count, liver function tests, renal function tests, serum ferritin, C-reactive proteins and hepatitis markers were taken.

Specific tests for evaluation of atherosclerosis were performed and included 12-h fasting lipid profile, serum Osteoprotegerin (OPG) assay, and carotid artery intimamedia thickness. All blood sampling for patients were performed at the day before red blood cell transfusion.

Lipid profile was taken after at least $12 \mathrm{~h}$ overnight fasting, it was performed by endpoint method (colorimetric method) and included; total serum cholesterol, high density lipoprotein- cholesterol (HDL-C), serum triglyceride (TG). Low density lipoprotein -cholesterol (LDL-C) was estimated using Friedewald and Levyformula [17] by calculation of (TG)-(TG/5)-(HDL-C). Atherogenic index of plasma (AIP) is the ratio calculated as log (TG/HDLC). Serum samples for assay of OPG were separated and stored at $-20 \mathrm{C}^{0}$. It was performed using Human OPG ELISA Kit, Boster Biological Technology Co., Ltd. USA.

Carotid artery intima-media thickness (CAIMT) measurements were performed for all participants by the same experienced vascular radiologist who was blinded to the clinical and laboratory details of the examined children. Duplex ultrasound B-mode and color-coded duplex sonography were performed using a (GE LOGIC P5) ultrasound system with a $12.0 \mathrm{MHz}$ linear array transducer.

\section{Statistical analysis}

All data were analyzed using SPSS 22.0 for windows (SPSS Inc., Chicago, IL USA) and MedCal 13 for windows (MedCal software bvba). Continuous variables were expressed as mean $\pm \mathrm{SD}$ while categorical variables were expressed as number (percentages). Continuous variables were checked for normality using Shapiro-Wilk test. Independent student- $t$ test was used to compare the normally distributed variables while Mann-Whitney $U$ (MW) test was used to compare non-normally distributed variables between two groups. Categorical variables were compared by using Chi-square test $\left(X^{2}\right)$. Pearson' correlation coefficient and Spearman' rank correlation were used to assess relationship between normally distributed and nonnormally distributed variables respectively. All tests are two sided, and $p<0.05$ was considered statistically significant.

\section{Results}

Sixty-five B-thalassemia major (B-TM) patients were recruited in the current work, their mean age was $9.5 \pm$ 3.7 years (ranged 5-18 years), and $57 \%$ of them were males. All of them were transfusion-dependent with illness duration ranged from 4-17 years (mean 8.5 \pm 3.8 years), almost half of them (50.7\%) were on every
4 weeks transfusion regimen, 34\% were on 3 weekly regimen while for the remaining $15.3 \%$ cases every two weeks transfusion was needed to keep target hemoglobin. Deferiprone was used as iron chelation in $49 \%$ of them, $45 \%$ used Deferasirox while the remaining 6\% were still using desferrioxamine as iron chelation therapy.

Results of B-TM patients' clinical evaluations, routine and specific laboratory investigations were compared with those of fifty, age and gender, matched healthy children. Apart from height, no significant difference could be detected atdemographic or anthropometric measures between patients and controls as shown in Table 1. On the contrary, significant differences were documented when results of complete blood count and routine chemical analysis were evaluated as displayed in Table 2. B-TM patients had significantly higher white blood cell count and platelets but much lower hemoglobin concentration than healthy comparisons. Almost thirty fold rise in serum ferritin was reported $(2490 \pm 1579 \mathrm{ng} / \mathrm{dl}$ vs $83 \pm 32 \mathrm{ng} / \mathrm{dl}$, $p=0.001$ ) for cases than controls. Significant rise in hepatic enzymes, total bilirubin and C-reactive protein were also revealed in patients group than healthy peers.

Significantly higher serum triglyceride $(128 \pm 20$ vs $101 \pm$ $7 \mathrm{mg} / \mathrm{dl}, p=0.009)$ and calculated atherogenic index of plasma $(0.45 \pm 0.12$ vs $0.22 \pm 0.04, p=0.001)$ were recorded in patients than comparisons. On the contrary, total serum

Table 1 Demographic data and Anthropometric measures of the studied groups

\begin{tabular}{|c|c|c|c|c|}
\hline Character & $\begin{array}{l}\text { Patients } \\
(N=65)\end{array}$ & $\begin{array}{l}\text { Controls } \\
(N=50)\end{array}$ & Test & $p$-value \\
\hline \multicolumn{5}{|l|}{ Age (years) } \\
\hline Mean \pm SD & $9.5 \pm 3.7$ & $10.4 \pm 3.7$ & $M W=-0.348$ & 0.729 \\
\hline Range & $5-18$ & $5-18$ & & \\
\hline \multicolumn{5}{|l|}{ Sex No (\%) } \\
\hline Male & 37 (57\%) & $34(68 \%)$ & $x^{2}=1.048$ & 0.306 \\
\hline Female & $28(43 \%)$ & $16(32 \%)$ & & \\
\hline \multicolumn{5}{|c|}{ Residence No (\%) } \\
\hline Urban & 25 (38.5\%) & $23(46 \%)$ & $x^{2}=0.062$ & 0.803 \\
\hline Rural & 40 (61.5\%) & $27(54 \%)$ & & \\
\hline \multicolumn{5}{|l|}{ Weight (Kg) } \\
\hline Mean \pm SD & $27.5 \pm 8.1$ & $33.8 \pm 10.8$ & $t=-1.76$ & 0.085 \\
\hline Range & $14-45$ & $19-60$ & & \\
\hline \multicolumn{5}{|l|}{ Height (cm) } \\
\hline Mean \pm SD & $114.7 \pm 21.8$ & $132 \pm 22$ & $t=-2.15$ & 0.038 \\
\hline Range & $95-155$ & $100-168$ & & \\
\hline \multicolumn{5}{|l|}{ BMI $\left(\mathrm{Kg} / \mathrm{m}^{2}\right)$} \\
\hline Mean \pm SD & $18.1 \pm 2.2$ & $21.5 \pm 6.9$ & $\mathrm{MW}=1.45$ & 0.191 \\
\hline Range & $16-21$ & $16-33$ & & \\
\hline
\end{tabular}

MW Mann Whitney $U$ test, $\chi^{2}$ Chi-square test, $p<0.05$ is significant, $t$ independent Student $t$-test, $B M I$ Body mass index 
Table 2 Hematological and biochemical parameters of the studied groups

\begin{tabular}{|c|c|c|c|c|}
\hline Parameter & $\begin{array}{l}\text { Patients } \\
(N=65)\end{array}$ & $\begin{array}{l}\text { Controls } \\
(N=50)\end{array}$ & Test & $p$-value \\
\hline \multicolumn{5}{|c|}{$\mathrm{WBC}\left(\times 10^{3} / \mathrm{mm}^{3}\right)$} \\
\hline Mean \pm SD & $11.3 \pm 4.6$ & $7.3 \pm 1.8$ & $\mathrm{MW}=2.5$ & 0.013 \\
\hline Range & $9-18.3$ & $5-9$ & & \\
\hline \multicolumn{5}{|l|}{$\mathrm{Hb}(\mathrm{gm} / \mathrm{dl})$} \\
\hline Mean \pm SD & $6.8 \pm 0.9$ & $12.6 \pm 0.7$ & $t=-17.5$ & $<0.001$ \\
\hline Range & $5-8.3$ & $11.8-14.2$ & & \\
\hline \multicolumn{5}{|c|}{$\operatorname{PLT}\left(\times 10^{3} / \mathrm{mm}^{3}\right)$} \\
\hline Mean \pm SD & $478.4 \pm 279.4$ & $276 \pm 77.6$ & $\mathrm{MW}=2.2$ & 0.030 \\
\hline Range & $136-1428$ & $170-405$ & & \\
\hline \multicolumn{5}{|l|}{ SGOT (IU/L) } \\
\hline Mean \pm SD & $52.3 \pm 39.4$ & $30.4 \pm 6.8$ & $\mathrm{MW}=2.74$ & 0.020 \\
\hline Range & $9-160$ & $20-40$ & & \\
\hline \multicolumn{5}{|l|}{ SGPT (IU/L) } \\
\hline Mean \pm SD & $46.4 \pm 38.4$ & $29.7 \pm 6.8$ & $\mathrm{MW}=2.36$ & 0.020 \\
\hline Range & $8-155$ & $19-38$ & & \\
\hline \multicolumn{5}{|c|}{ Total bilirubin (mg/dl) } \\
\hline Mean $\pm S D$ & $1.4 \pm 0.6$ & $0.6 \pm 0.2$ & $\mathrm{MW}=3.84$ & 0.001 \\
\hline Range & $0.6-2.8$ & $0.4-0.9$ & & \\
\hline \multicolumn{5}{|l|}{ Direct bilirubin } \\
\hline Mean \pm SD & $0.2 \pm 0.1$ & $0.2 \pm 0.1$ & $M W=-0.147$ & 0.885 \\
\hline Range & $0.1-0.5$ & $0.1-0.4$ & & \\
\hline \multicolumn{5}{|c|}{ Total Proteins (gm/dl) } \\
\hline Mean \pm SD & $6.1 \pm 1.3$ & $6.8 \pm 0.8$ & $t=-1.462$ & 0.154 \\
\hline Range & $4.5-8$ & $5.2-8$ & & \\
\hline \multicolumn{5}{|l|}{ Urea (mg/dl) } \\
\hline Mean \pm SD & $29.6 \pm 6.9$ & $27.5 \pm 5.6$ & $M W=-0.167$ & 0.847 \\
\hline Range & $21-41$ & $15-37$ & & \\
\hline \multicolumn{5}{|c|}{ Creatinine (mg/dl) } \\
\hline Mean \pm SD & $0.5 \pm 0.3$ & $0.4 \pm 0.2$ & $t=0.341$ & 0.766 \\
\hline Range & $0.3-0.8$ & $0.2-0.7$ & & \\
\hline \multicolumn{5}{|l|}{ CRP } \\
\hline Mean \pm SD & $5.7 \pm 5.7$ & $0.9 \pm 0.9$ & $M W=2.6$ & 0.012 \\
\hline Range & $1-21$ & $0-2$ & & \\
\hline \multicolumn{5}{|c|}{ S. ferritin (ng/dl) } \\
\hline Mean \pm SD & $2490 \pm 1579$ & $83 \pm 32$ & $M W=4.7$ & $<0.001$ \\
\hline Range & $653-8406$ & $30-127$ & & \\
\hline
\end{tabular}

MW Mann Whitney $U$ test, SGOT Aspartate transaminase, $t$ independent Student $t$-test, SGPT Alanine transaminase, $p<0.05$ is significant, CRP C- reactive protein

cholesterol $(116 \pm 16$ vs $143 \pm 5, p<0.001)$, low density lipoprotein-cholesterol (LDL-C) $(44 \pm 9$ vs $73 \pm 6, p<0.001)$ and high density lipoprotein cholesterol (HDL-C) (39 \pm 2 vs $61 \pm 5, p<0.001)$, were significantly lowered in patients versus normal controls as displayed in Fig. 1.
ELISA assay of serum Osteoprotegerin (OPG) revealed significantly higher levels for thalassemia patients than matched healthy controls ( $427 \pm 102$ vs $324 \pm 126 \mathrm{pg} / \mathrm{ml}$, $p=0.02)$ as expressed in Fig. 2. Of particular interest is the obvious positive correlation between OPG levels and CAIMT of both sides (Rt r 0.549, $p=0.001$ \&Lt r 0.479, $p=0.001)$ and also with serum triglycerides ( $\mathrm{r} 0.374, p=$ 0.03 ) as shown among other parameter in Table 3.

Duplex ultrasonographic Carotid arteries intima media thickness (CAIMT) of both side were significantly increased for patients (Rt $0.62 \pm 0.2$ vs. $0.29 \pm 0.07 \mathrm{~mm}, p=0.001$ \& Lt $0.66 \pm 0.17$ vs $0.29 \pm 0.05 \mathrm{~mm}, p=0.001$ ) when compared with healthy controls as described in Table 4. These findings have pointed to the high frequency of atherosclerosis among thalassemia group. Documented positive correlation of CAIMT with serum triglyceride andatherogenic index of plasma have supported the previous data. Significant positive relationship between CAIMT and S. Osteoprotegerin (OPG) was also ascertained in our thalassemia patients as shown in Table 5.

\section{Discussion}

In the current study we tested the hypothesis that chronic hemolytic anemia may lead to vascular damage and premature atherosclerosis in B-TM patients. Our results documented significantly higher carotid artery intima-media thickness (CAIMT) of both sides among B-TM patients than matched controls $(p<0.001)$, a finding that provided evidence to the real risk of atherosclerosis for these patients.

As endothelial dysfunction and increased arterial thickness are important risk factors for the development of atherosclerosis [18], several studies have reported the measurement of arterial intima-media thickness as a good determinant of subclinical atherosclerosis [19-21]. Increased CAIMT have been described as a mirror of atherosclerotic burden, and a predictor of subsequent events including myocardial infarction and stroke $[8,19]$. Because of its quantitative value, it has been used more and more in clinical trials [8], and noticeably trusted in detecting pre-clinical (asymptomatic) atherosclerosis in clinical setting [7]. Depending on the aforementioned advantages of this modality, our team and other researchers [19-21] have used this technique as a gold standard for early detection of atherosclerosis. Few studies have been performed on adults and adolescent patients with B-TM patients and showed significant increase in their CAIMT $[21,22]$ but to the best of our knowledge this work is the first to evaluate premature atherosclerosis in Egyptian BTM children with this modality.

There are limited data concerning atherosclerosis risks in these patients, we evaluated clinical and laboratory parameters that may be relevant to vascular injury and atherogensis. Clinical characteristics didn't show any difference from 


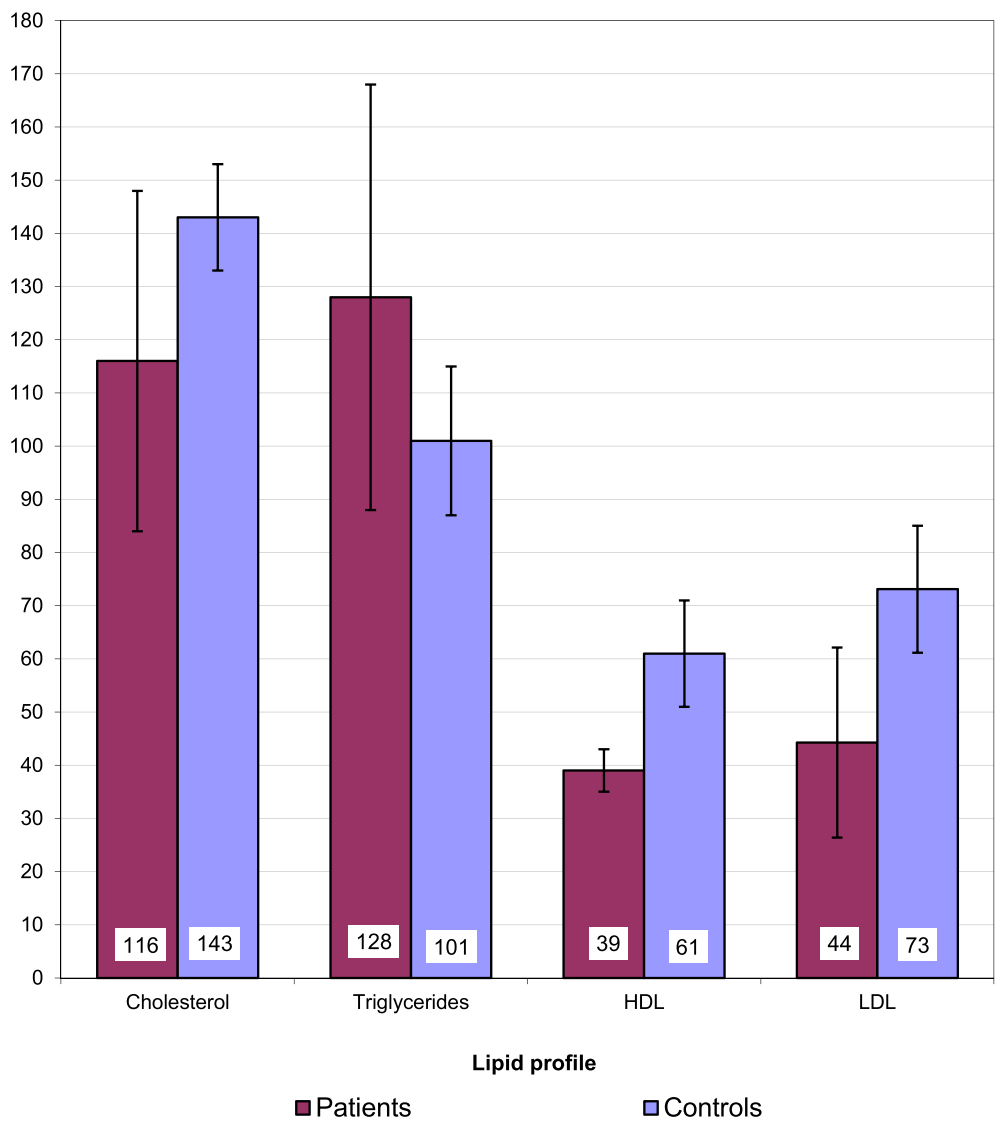

Fig. 1 Lipid profile distribution of the studied groups: bar represent mean; Y-error bar represent 95\% confidence interval of mean

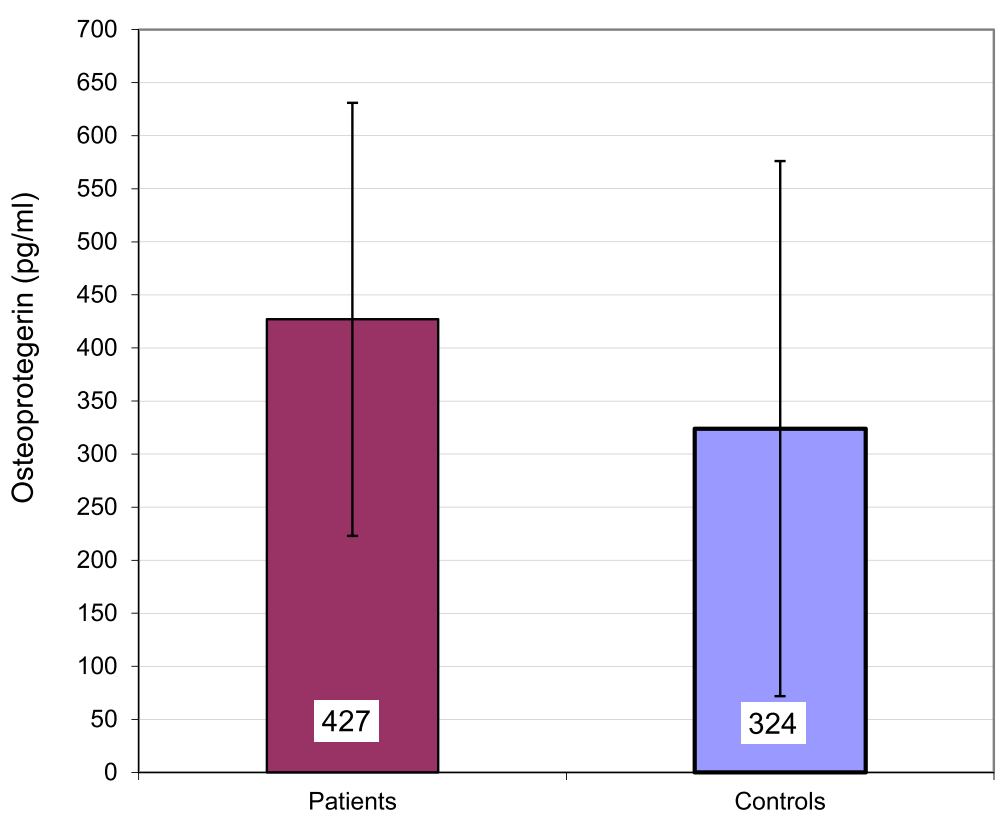

Fig. 2 Serum Osteoprotegerin ( $\mathrm{pg} / \mathrm{ml}$ ) distribution of the studied groups: bar represent mean; Y-error bar represent $95 \%$ confidence interval of mean 
Table 3 Correlations between Osteoprotegerin (OPG) and different parameters in the patients

\begin{tabular}{lcc}
\hline Parameters & \multicolumn{2}{c}{ Osteoprotegerin (OPG) } \\
\cline { 2 - 3 } & $r$ & $p$-value \\
\hline Age & -0.082 & 0.649 \\
Duration of disease (years) & -0.063 & 0.729 \\
Body mass index (BMI) & +0.331 & 0.060 \\
Serum ferritin & -0.086 & 0.633 \\
Serum cholesterol & -0.205 & 0.253 \\
High density lipoproteins (HDL-C) & -0.263 & 0.140 \\
Low density lipoproteins (LDL-C) & $-0.318^{\mathrm{a}}$ & 0.071 \\
Triglycerides (TG) & +0.374 & 0.032 \\
Atherogenic index of plasma (AIP) & +0.263 & 0.140 \\
C-reactive protein (CRP) & -0.173 & 0.336 \\
Right carotid artery intima media & +0.549 & 0.001 \\
thickness (Rt. CAIMT) & & \\
Left carotid artery intima media & +0.479 & 0.001 \\
thickness (Lt. CAlMT) & & \\
Aspartate transaminase (AST) & -0.170 & 0.344 \\
Alanine transaminase (ALT) & -0.294 & 0.097 \\
\hline$r$ correlation coefficient \\
aPearson's correleation coefficient
\end{tabular}

controls, or significant correlations with CAIMT. However, results of the hematologic and biochemical investigations of our B-TM patients displayed very peculiar metabolic model with; significant anemia, sky high increase in serum ferritin, and dyslipidemia which presented as high triglyceride and atherogenic index of plasma (AIP) but associated with low total cholesterol, LDL-C and HDL-C in patients as compared with comparisons.

Hemolytic anemia might be a predisposing factor for atherosclerosis by several mechanisms. First, erythrocyte release arginase enzyme during hemolysis coupled with the liberation of cell -free hemoglobin [23] contribute to dysregulated arginine metabolism with low arginine/ornithine ratio. These metabolic derangements limit the availability of arginine to nitric oxide synthase and lead to vascular dysfunction by disturbing the bioavailability of nitric oxide (NO) [24, 25]. Second, anemia was described

Table 4 Radiological parameters of the studied group

\begin{tabular}{|c|c|c|c|c|}
\hline CAMIT (mm) & Patients $(N=65)$ & Controls $(N=50)$ & MW & $p$-value \\
\hline \multicolumn{5}{|c|}{ Right carotid artery (IMT) } \\
\hline Mean \pm SD & $0.62 \pm 0.20$ & $0.29 \pm 0.07$ & 5.142 & $<0.001$ \\
\hline Range & $0.4-1.1$ & $0.2-0.4$ & & \\
\hline \multicolumn{5}{|c|}{ Left carotid artery (IMT) } \\
\hline Mean \pm SD & $0.66 \pm 0.17$ & $0.29 \pm 0.05$ & 6.609 & $<0.001$ \\
\hline Range & $0.4-1.2$ & $0.2-0.4$ & & \\
\hline
\end{tabular}

MW Mann Whitney $U$ test, CAMIT Carotid artery intima media thickness, $p<0.05$ is significant, $\mathrm{mm}$ millimeter
Table 5 Correlation between carotid artery intima media thickness and different parameters of the patients

\begin{tabular}{|c|c|c|c|c|}
\hline \multirow[t]{2}{*}{ Parameters } & \multicolumn{2}{|c|}{ Rt. CAIMT } & \multicolumn{2}{|c|}{$\underline{\text { Lt CAIMT }}$} \\
\hline & $r$ & $\mathrm{p}$ & $r$ & $\mathrm{p}$ \\
\hline Age & +0.172 & 0.340 & +0.083 & 0.646 \\
\hline Disease duration (years) & +0.195 & 0.276 & +0.125 & 0.487 \\
\hline BMI & +0.123 & 0.494 & +0.143 & 0.427 \\
\hline Serum ferritin & +0.200 & 0.264 & +0.059 & 0.744 \\
\hline Serum cholesterol & -0.086 & 0.633 & -0.087 & 0.631 \\
\hline TG & +0.275 & 0.121 & +0.453 & 0.008 \\
\hline HDL-C & +0.164 & 0.361 & +0.048 & 0.790 \\
\hline LDL-C & -0.235 & 0.188 & -0.225 & 0.207 \\
\hline AIP & +0.155 & 0.388 & +0.446 & 0.009 \\
\hline CRP & -0.115 & 0.525 & -0.129 & 0.473 \\
\hline OPG & +0.411 & 0.018 & +0.390 & 0.025 \\
\hline SGOT & +0.387 & 0.026 & +0.003 & 0.985 \\
\hline SGPT & +0.307 & 0.082 & +0.022 & 0.903 \\
\hline
\end{tabular}

CAMIT carotid artery intima media thickness, BMI Body mass index, $r$ Spearman's rank correleation coefficient, TG Triglycerides, $p<0.05$ is significant, AIP Atherogenic index of plasma, OPG osteoprotegerin, SGOT Aspartate transaminase, SGPT Alanine transaminase, CRP C-reactive protein, $H D L-C$ High density lipoproteins cholesterol, LDL-C Low density lipoprote

as risk factor of hypertriglyceridemia due to its negative impact on extra-hepatic lipolytic activity [26].

Significantly high S. ferritin was found among B-TM patients in our series, this finding was in agreement with many previous researchers $[27,28]$. Poor compliance to iron chelation was obvious among our patient (51\%), represented an important and probably correctable cause of iron overload. High iron burden may increase patient's risk for atherosclerosis by excess free radicle production [29, 30]. Moreover, Mansi and Aburjai documented positive correlation between $\mathrm{S}$. ferritin and triglyceride level "an important predictor of atherosclerosis" [31]. Against our expectation, no significant correlation could be detected between CAIMT and S. ferritin, and similar result was previously documented by Tantawy and his colleague [21]. This data suggested that non-transferrin bound iron accumulation at cellular level with subsequent macrophage activation may be the triggering for development of atherosclerosis rather than high serum ferritin level [32].

Children with beta thalassemia are at increased risk of developing premature atherosclerosis because of dyslipidemia [21]. Lipid profiles have been described by several investigators but with conflicting results [26, 33-36]. Most of them including our team have shared common findings of lowered total cholesterol, LDL-C, HDL-C [27, 34-39]. Values from our B-TM patients and many other researchers showed elevated triglyceride levels (TG) [33, 34, 36-38], while others described TG levels as being not- significantly different from controls [35, 39]. CAIMT in the present study was positively correlated with S. TG and atherogenic index of plasma. 
Dyslipidemia in thalassemia patients has been previously explained by several researchers who speculated different pathophysiologic pathways; plasma dilution because of anemia, accelerated erythropoiesis with excess cholesterol uptake by macrophages and histocytes of the reticuloendothelial system, defective liver synthetic function because of iron overload, macrophage activation with cytokine release and hormonal disturbance [33, 40, 41] while reduced extra-hepatic lipolytic activity might be responsible for the increased TG in B-TM patients [33].

It was surprising that our B-TM patients had early atherosclerosis despite low LDL-C, this observation is possibly due to oxidative change of LDL-C to "atherogenic LDL" by unbalanced oxidant- antioxidant milieu in thalassemia patients [42-45].

Atherogenic index of plasma (AIP) is a marker of atherogenicity since it is related directly to atherosclerosis; it is calculated as log (TG/HDL-C). Hypertriglyceridemia will increase the activity of hepatic lipase which results in HDL-C degradation with subsequent increased risk of coronary atherosclerosis [46]. In the present work, there was significant increase in AIP ratio for BTM patients than for the healthy controls and also, it displayed positive correlation with CAIMT. These finding was in agreement with those by Najajou et al. and Daniel et al. who reported high predictive value of AIP for development of atherosclerosis $[47,48]$.

Rt. CAIMT showed significant correlation with SGOT (AST) but not with other liver enzyme, these findings might point to hemolysis in triggering atherosclerosis in our patients as hemolysis is the main source of elevated AST [49].

In the current study we had the chance to ascertain that Osteoprotegerin (OPG) was significantly raised in patients as compared with comparisons $(P<0.001)$, and to document the positive correlation that displayed between OPG, CIMT, and TG. Elevated OPG level was suggested; as a marker of arterial damage [50], as predictor of coronary artery diseases, [51] and overall cardiovascular morbidity and mortality [52], but as far as our knowledge our team was the first to investigate the relationship between atherosclerosis as expressed by CIMT and OPG in B-TM patients.

Results from two large cohort studies for the validity of OPG assay as a predictor of atherosclerosis and coronary artery diseases were supporting for its clinical application in predicting atherosclerosis in asymptomatic high-risk individuals [53], [54]. Positive correlation between OPG and CIMT observed among our B-TM patientshighlighted its importance as promising biomarker of subclinical atherosclerosis detection.

\section{Conclusions}

Premature subclinical atherosclerosis was documented among Egyptian beta thalassemia major patients by evaluating their carotid artery intima media thickness (CAIMT). It was correlated well with dyslipidemia and serum osteoprotogrin, a finding that highlighted the possible validity of OPG assay as an early predictor of atherosclerosis in thalassemia children. However, multicenter wide scale research is warranted to evaluate OPG assay cutoff value, its sensitivity and specificity as reliable biomarker for diagnosis of atherosclerosis.

\section{Abbreviations}

B-TM: Beta-thalassemia major.; CAIMT: Carotid artery intima media thickness; OPG: Osteoprotegerin

\section{Acknowledgements}

Funding

No funds were available to the current work.

Availability of data and materials

available upon request.

\section{Authors' contributions}

LMS, put the conception and design of the study, shared in acquisition, analysis and interpretation of data and drafting of the manuscript. AA, MA, MN, WM: shared in acquisition, analysis and interpretation of data. HS, ME, NMK: shared in drafting of the manuscript and revising it critically for important intellectual contents. OD was responsible for duplex ultrasound and its interpretation. OA was responsible for laboratory testing and its interpretation. All authors have given final approval of the version to be published.

\section{Competing interests}

The authors declare that they have no competing interests.

\section{Consent for publication}

we have obtained consent to publish from the participant (or legal parent or guardian for children) to report individual patient data.

\section{Ethics approval and consent to participate}

The study protocol was approved by the research and ethical committee of Faculty of Medicine, Zagazig University and written informed consent was taken from parents or guardian of each participant.

\section{Author details}

${ }^{1}$ Pediatrics and Pediatric Hematology and Oncology, Faculty of Medicine, Zagazig University, Zagazig, Egypt. ${ }^{2}$ Radiology Department, Zagazig University, Zagazig, Egypt. ${ }^{3}$ Pediatrics Department, Zagazig University, Zagazig, Egypt. ${ }^{4}$ Pediatric Department, Cairo University, Giza, Egypt. ${ }^{5}$ Pediatric Department, Tanta University, Tanta, Egypt. ${ }^{6}$ Biochemistry Department, Zagazig University, Zagazig, Egypt.

Received: 23 October 2015 Accepted: 23 February 2017

Published online: 09 March 2017

References

1. Hussein G, Fawzy M, Sersfi TE, et al. Rapid detection of beta thalassaemia alleles in Egypt using natural or amplified created restriction sites and direct sequencing: a step in disease control. Hemoglobin. 2007;31(1):49-62.

2. Muncie $\mathrm{Jr} \mathrm{HL}$, Campbell J. Alpha and beta thalassemia. Am Fam Physician. 2009;80:339-44

3. Cighetti G, Duca L, Bortone L, et al. Oxidative status and malondialdehyde in thalassemia patients. Eur J Clinlnv. 2002;32 suppl 1:55-60.

4. Hansson GK. Inflammation, atherosclerosis, and coronary artery disease. N Engl J Med. 2005;352:1685-95.

5. Manios E, Tsivgoulis G, Koroboki E, et al. Impact of prehypertension on common carotid artery intima-media thickness and left ventricular mass. Stroke. 2009;40:1515-8.

6. Cunningham KS, Gotlieb Al. The role of shear stress in the pathogenesis of atherosclerosis. Lab Invest. 2005;85:9-23. 
7. Aggoun Y, Szezepanski I, Bonnet D. Noninvasive assessment of arterial stiffness and risk of atherosclerotic events in children. Pediatr Res. 2005;58(2):173-8.

8. Hahalis G, Kremastinos DT, Terzis G, et al. Global vasomotor dysfunction and accelerated vascular aging in b-thalassemia major. Atherosclerosis. 2008;198(2):448-57.

9. Loizou CP, Pattichis CS, Nicolaides AN, Pantziaris M. Manual and automated media and intima thickness measurements of the common carotid artery. IEEE Trans UltrasonFerroelectrFreq Control. 2009;56:983-94.

10. Konstantino Y, Wolk R, Terra SG, Nguyen TT, Fryburg DA. Nontraditional biomarkers of atherosclerosis in stable and unstable coronary artery disease, do they differ? Acute Card Care. 2007;9:197-206.

11. Rasmussen LM, Ledet T. Osteoprotegerin and diabetic microangiopathy. Horm Metab Res. 2005;37(1):90-S94

12. Zannettino $C A$, Holding AC, Diamond $P$, et al. Osteoprotogrin (OPG) is localized to the Weibel-Palade bodies of human vascular endothelial cells and is physically associated with von Willebrand factor. J Cell Physiol. 2005;204:714-23.

13. Kaden JJ, Bickelhaupt S, Grobholz R, et al. Receptor activator of nuclear factor kappaB ligand and osteoprotegerin regulate aortic valve calcification. J Mol Cell Cardiol. 2004:36:57-66.

14. Morony $S$, Tintut $Y$, Zhang $Z$, et al. Osteoprotegerin inhibits vascular calcification without affecting atherosclerosis in Idlr (-/-) mice. Circulation. 2008;117:411-20

15. Min H, Morony S, Sarosi l, et al. Osteoprotegerin reverses osteoporosisby inhibiting endosteal osteoclasts and prevents vascular calcification by blocking a process resembling osteoclastogenesis. J ExpMed. 2000;192:463-74.

16. Borgna-Pignatti C, Galanello R. Wintrobe's clinical hematology. 11. Vol. 42. Thalassemias and related disorders: quantitative disorders of hemoglobin synthesis. Philadelphia: Lippincott Williams \& Wilkins; 2004. pp. 1319-65.

17. Friedewald W, Levy RI, Freidrickson DS. Estimation of concentration of lowdensity lipoprotein in plasma, without use of preparative ultracentrifuge. Clin Chem. 1972;18:499-502.

18. Gursel O, Kureli AE, Tascilar E, et al. Premature atherosclerosis in children with B thalassemia major. J PediatrHematoloncol. 2012;34(8):630-4.

19. Fin AV, Kolodgie VR. Correlation between carotid intima-media thickness and atherosclerosis: a point of view from pathology. AtherisclerThromVascBiol. 2010;30:177-81.

20. Jarvisalo MJ, L. Jartti, K. Nanto-Salonen, K. Irjala, T. Ronnemaa, J. J. Hartiala, D. S. Celermajer, O. T. Raitakari, M. J. Jarvisalo, L. Jartti, K. Nanto-Salonen, K. Irjala, T. Ronnemaa, J. J. Hartiala, D. S. Celermajer, O. T. Raitakari (2001). Increased aortic intima-media thickness: a marker of preclinical atherosclerosis in high-risk children. Circulation 104 (24):2943-2947.

21. Cheung TF, Chow PC, Chan GC, et al. Carotid intima media thickness is increased and related to arterial stiffness in patients with beta thalassemia major. Br J Hematol. 2006;135:732-4.

22. Tantawy AG, Adly AM, El Maaty GA, et al. Subclinical atherosclerosis in young beta thalassemia patients. Hemoglobin. 2009;33:463-74.

23. Cheung YF, Chan GC, Ha SY. Arterial stiffness and endothelial function in patients with beta thalassemia major. Circulation. 2002;106:2561-6.

24. Reiter CD, Wang X, Tanus-Santos JE, et al. Cell free hemoglobin limits nitric oxide bioavailability in sickle cell disease. Nat Med. 2002;8:1383-9.

25. Morris CR, Kuypers FA, Gregory J, Kato GJ, et al. Hemolysis-associated pulmonary hypertension in thalassemia. Ann N Y AcadSci. 2005;1054:481-5.

26. Morris CR, Kim HY, Klings ES, Wood J, et al. Dysregulated arginine metabolism and cardiopulmonary dysfunction in patients with thalassemia. Br J Hematol. 2015;169(6):887-98.

27. Ragab SM, Safan MA, Sherif AS. Lipid profile in beta thalassemia children. Menofia Medical J. 2014;27:66-72.

28. Borgna-pignatti C, Cappellini M, De Stefano $P$, et al. Survival and complications in thalassemia. Ann N Y Acad Sci. 2005;1054:40-7.

29. Vladislav S, Rapnael H, Caina L. Renal function in children with B-thalassemia major and thalassemia intermedia. PediatrNephrol. 2008;23:1847-51.

30. Livrea MA, Tesorere L, Maggio A, et al. Oxidative modification of low-density lipoprotein and atherogenic risk in B-thalassemia. Blood. 1998;92(10):3936-42.

31. Anca V, Arica S, Ozer C, et al. Serum lipid values in children with beta thalassemia major. PediatTherapeut. 2010;2(5):130-3.

32. Mansi $M$, Aburjai TA. Lipid profile in Jordanian children with beta thalassemia major. Int J HematolOncol. 2008;18:93-8.

33. Paganga $G$, Evans $C$, Rule $R$, et al. The interaction between ruptured erythrocytes and low density lipoproteins. FEBS. 1992;303:154.

34. Al Quobaili F, Imad E. AbouAsali. Serum levels of lipid and lipoprotein in Syrian patients with B-thalssemia major. Saudi Med J. 2004;25(7):871-5.
35. Khubchandani A, Solanki V, Solanki M, et al. Estimation of serum lipid profiles in patients with beta thalassemia major. Int J Res Med. 2014:3(2):65-7.

36. Haghpanah S, Davani M, Samadi B, et al. Serum lipid profiles in patients with beta thalassemia major and intermedia in southern Iran. JRMS. 2010;15:150-4.

37. Shams S, Ashtiani MT, Monajemzadeh M, Koochakzadeh L, Irani H, Jafari F, Mohseni A. Evaluation of serum insulin, glucose, lipid profile, and liver function in $\beta$-thalassemia major patients and their correlation with iron overload. Labmedicine. 2010;41(80):486-9.

38. Hartman C, Tamary H, Tamir A, et al. Hypocholesterolemia in children and adolescents with beta-thalassemia intermedia. J Pediatr. 2002;141(4):543-7.

39. Ricchi P, Ammirabile M, Spasiano A, et al. Hypocholesterolemia in adult patients with thalassemia: a link with the severity of genotype in thalassemia intermedia patients. Europ J Hematol. 2009;82:219-22.

40. Amendola G, Danise P. Tordisco N, et al. Lipid profile in beta thalassemia intermedia patients: correlation with erythroid bone marrow activity. Int J Lab Hematol. 2007;29:172-6.

41. Shalev H, Kapelushnik J, Moser A, et al. Hypocholesterolemia in chronic anemia with increased erythropoieticactivity. Am J Hematol. 2007;82:199-202.

42. Tselepis DA, Hahalis G, Tellis CC, et al. Plasma level of lipoprotein associated phospholipase A2 are increased in patients with B-thalassemia. J Lipid Res. 2010:51:3331-41.

43. Chrysohou C, Panagiotakos DB, Pistavos C, et al. Distribution of serum lipid and lipoprotein in patients with beta thalassemia major: an epidemiological study in young adults from Greece. Lipid Health Dis. 2004;3:3-8.

44. Jacobs A. The pathology of iron overload. In: Jacobs A, Wor-wood M, editors. Iron in biochemistry and medicine II. New York: Academic; 1980. p. 427.

45. Livrea MA, Tesoriere L, Pintaudi AM, et al. Oxidative stress and antioxidant status in B-thalassemia major: iron overload and depletion of lipid soluble antioxidant. Blood. 1996;88:3608.

46. Susanti E, Donosepoetro M, Patellong I, et al. Differences between several atherogenic parameters in patients with controlled and uncontrolled type 2 Diabetes Mellitus. Med J Indones. 2010;19(2):103-8.

47. Njajou O, Kanaya AM, Holvoet P, et al. Association between oxidized LDL-C, obesity and type 2 diabetes. Diabetes Metab Res Rev. 2009;25(8):733-9.

48. Daniels LB, Laughlin G, Sarno MJ. Lp- PLA2 is an independent predictor of incident coronary heart disease in apparently healthy older population. J Am Col Cadiol. 2008;51:913-9.

49. Burris Ashwood ER, Burns DE. Textbook of clinical chemistry and molecular diagnostics. 4th ed. St louis: Elseiver, Saunders; 2006.

50. Chen NX, Moe SM. Arterial calcification in diabetes. Current Diabetes Reports. 2003;3:28-32.

51. Breland UM, Hollan I, Saatvedt K, et al. Inflammatory markers in patients with coronary artery disease with and without inflammatory rheumatic disease. Rheumatology. 2010;49:1118-27.

52. Nybo M, Rasmussen LM. The capability of plasma osteoprotegerinas as predictor of cardiovascular disease: a systematic literature review. Eur J Endocrinol. 2008:159:603-8.

53. Semb AG, Ueland T, Aukrust $P$, et al. Osteoprotegerin and soluble receptor activator of nuclear factor-ligand and risk for coronary events: a nested case-control approach in the prospective EPIC-Norfolk population study 1993-2003. Arterioscler Thromb Vasc Biol. 2009;29(6):975-80.

54. Mogelvang R, Pedersen SH, Flyvbjerg A, et al. Comparison of osteoprotegerin to traditional atherosclerotic risk factors and high-sensitivity $\mathrm{C}$-reactive protein for diagnosis of atherosclerosis. Am J Cardiol. 2012;109:515-20.

\section{Submit your next manuscript to BioMed Central and we will help you at every step:}

- We accept pre-submission inquiries

- Our selector tool helps you to find the most relevant journal

- We provide round the clock customer support

- Convenient online submission

- Thorough peer review

- Inclusion in PubMed and all major indexing services

- Maximum visibility for your research

Submit your manuscript at www.biomedcentral.com/submit 